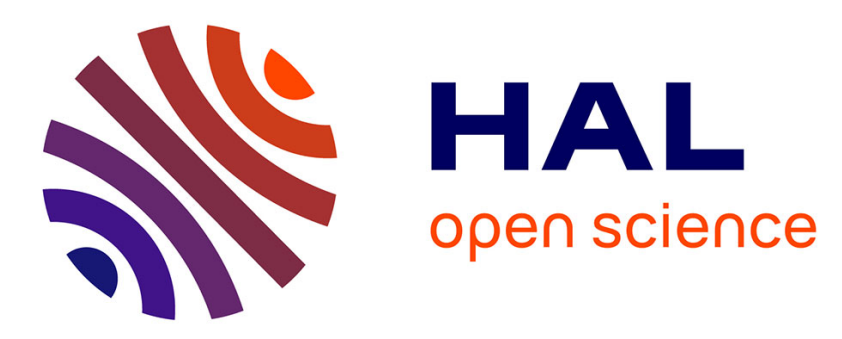

\title{
The Potential of 3D-MID Technology for Omnidirectional Inductive Wireless Power Transfer
}

Sergkei Kamotesov, Philippe Lombard, Vincent Semet, Bruno Allard, Mael Moguedet, Michel Cabrera

\section{- To cite this version:}

Sergkei Kamotesov, Philippe Lombard, Vincent Semet, Bruno Allard, Mael Moguedet, et al.. The Potential of 3D-MID Technology for Omnidirectional Inductive Wireless Power Transfer. 2018 13th International Congress Molded Interconnect Devices (MID), Sep 2018, Würzburg, Germany. 10.1109/ICMID.2018.8526962 . hal-02152067

\section{HAL Id: hal-02152067 https://hal.science/hal-02152067}

Submitted on 11 Jun 2019

HAL is a multi-disciplinary open access archive for the deposit and dissemination of scientific research documents, whether they are published or not. The documents may come from teaching and research institutions in France or abroad, or from public or private research centers.
L'archive ouverte pluridisciplinaire HAL, est destinée au dépôt et à la diffusion de documents scientifiques de niveau recherche, publiés ou non, émanant des établissements d'enseignement et de recherche français ou étrangers, des laboratoires publics ou privés. 


\section{The Potential of 3D-MID Technology for Omnidirectional Inductive Wireless Power Transfer}

\author{
Kamotesov Sergkei \\ Smart Plastic Products (S2P) \\ 5 Rue Pierre et Marie CURIE, \\ Belignat - BP 21107, \\ 01111 Oyonnax Cedex, France \\ sergkei.kamotesov@s-2p.com \\ Bruno Allard \\ Université de Lyon, INSA Lyon, \\ Université Claude Bernard Lyon 1, \\ CNRS, Ecole Centrale de Lyon, Ampère \\ F-69621, Villeurbanne, France \\ bruno.allard@insa-lyon.fr
}

\author{
Philippe Lombard \\ Université de Lyon, Université Claude \\ Bernard Lyon 1, CNRS, INSA Lyon, \\ Ecole Centrale de Lyon, Ampère \\ F-69621, Villeurbanne, France \\ philippe.lombard@univ-lyon1.fr \\ Maël Moguedet \\ Smart Plastic Products ( $S 2 P$ ) \\ 5 Rue Pierre et Marie CURIE, \\ Belignat - BP 21107, \\ 01111 Oyonnax Cedex, France \\ mael.moguedet@s-2p.com
}

\author{
Vincent Semet \\ Université de Lyon, Université Claude \\ Bernard Lyon 1, CNRS, INSA Lyon, \\ Ecole Centrale de Lyon, Ampère \\ F-69621, Villeurbanne, France \\ vincent.semet@insa-lyon.fr \\ Michel Cabrera \\ Université de Lyon, INSA Lyon, \\ Université Claude Bernard Lyon 1, \\ CNRS, Ecole Centrale de Lyon, Ampère \\ F-69621, Villeurbanne, France \\ michel.cabrera@insa-lyon.fr
}

\begin{abstract}
Omnidirectional inductive wireless charging system of a mobile is studied. Instead of using conventional planar coils printed on circuit boards, 3D Molded Interconnect Device (3D-MID) coils are used. The receiver is a single piece that has 3 elliptic inductors pointing in 3 different directions of the space. A half meter cubic box with 4 planar emitting inductors on 4 sides is used to transmit power at $6.78 \mathrm{MHz}$ to the receiver inside the cube, regardless to the position and orientation of the receiver. Measurement results show that the 3D-MD receiver can get a power of $1.4 \mathrm{~W}$ at $7.9 \%$ efficiency on most of the positions inside the box. When the receiver is at the central position and also in the corners of the box, there is little variation of the transferred power when the receiver turns $360^{\circ}$, which means that it is almost insensitive to angular misalignment. However, when the receiver moves from the center towards the corners, there is a drop or an increase of power, which means that there is a lack of uniformity of the power which transferred near the corners. Ways to improve this point are discussed. However, our conclusion is that 3D-MID technology is an interesting technology for replacing the planar coils used in conventional WPT receivers.
\end{abstract}

Keywords-Molded Interconnect Device - MID, Wireless Power Transfer - WPT, Omnidirectional, Inductance, 3D coils

\section{INTRODUCTION}

The powering of the increasing number of portable electronic devices is a major problem, which cannot be solved only by using more cables, more batteries, etc. Inductive Wireless Power Transfer (WPT) [1] is an attractive solution which has been already adopted by the consumer market. However, today's systems based on Qi and AirFuel standards are limited to unidirectional low range static charging since the receiver (the portable electronic device) has to be close to the emitter (Fig. 1) [2]. Indeed, the transferred power drops dramatically when the distance from emitter to receiver increases or when there is an angular misalignment. Thus, many efforts are focused on correcting these problems in order to expand the freedom of movement of the receiver. Furthermore, these systems use heavy and bulky planar coils that are hard to integrate in small electronic devices. That is why in this paper, we want to propose a solution with easy integrable 3D-Molded Interconnect Device (3D-MID) inductors that will help to increase the freedom of movement of the receiver, with the long-term goal to develop a viable solution for omnidirectional WPT.

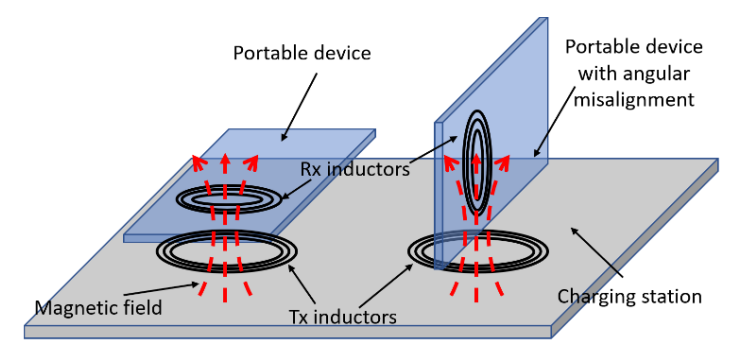

Fig. 1. Schematic of an inductive WPT charging system. On the left: efficient transmission of energy due to good coupling between the emitter Tx inductor and the receiver $\mathrm{Rx}$ inductor. On the right, poor transmission of energy due to bad coupling.

Omnidirectional charging has been already addressed in several papers. In [3], it is suggested to create a big emitting box which is powered by a single cubic inductor with a $3 \mathrm{D}$ design. A planar receiver of almost the same size as the emitter was able to catch power from any of the 6 sides of the cubic emitter. In [4] and [5], it is proposed to address the angular misalignment problem with a 3D design of the emitter. Indeed, 3 inductors were placed at $90^{\circ}$ from each other in order to transmit power to any direction. However, in ref [3-5], the directionality of emission is the only concern.

In other respects, in ref [6] and [7], the goal is to transmit power to mobile receivers situated on freely behaving animals used in behavioral neuroscience studies. They used an array of planar coils situated at the bottom of a cage to transmit power to planar coils situated on rodents in a big volume. Therefore, the transmission of power is limited to a short distance in the height and is sensitive to the receiver orientation.

In [8], we combined a big emitting box and a $3 \mathrm{D}$ receiving cube with 6 planar inductors on each side which have been made by assembling standard printed circuit boards. Results showed that we were able to power a single device in a big volume with $1.9 \mathrm{~W}$ regardless to the orientation. However, 3D coils are not easy to manufacture with conventional manufacturing methods and 3D-MID technology might be a good solution

Therefore, in this paper, we want to extend the study reported in [8], but this time we use a receiver with 3D-MID inductances pointing in 3 different directions instead of using inductances made of conventional printed circuit boards. On the emitting side, we kept the box with 4 wired emitting coils 
situated on 4 different sides of the box. The question here is to check if an omnidirectional receiver made with 3D-MID technology can get power inside the emitting box. For this, among other issues, it was necessary to determine if the quality factor of the 3D-MID inductances was sufficient for WPT applications.

Therefore, this paper is organized as follows. In the first section inductive WPT is briefly explained. In the second section, the experimental setup is described. In the third section, we show the measurement results.

\section{PRINCIPLE OF INDUCTIVE WIRELESS POWER TRANSFER}

In this section, the principal of resonant inductive wireless power transfer is briefly explained.

An inductive WPT circuit model is showed on Fig. 2 with two elements, the emitter and the receiver. Each of them has respectively an inductor $\left(L_{i}\right)$ and a capacitor $\left(C_{i}\right)$ that creates a resonant LC circuit. The inductors have an intrinsic resistance value $\left(R_{i}\right)$ that varies with the frequency. Different types of LC circuit configuration can be found in the literature [9]. However, we consider below the configuration "series resonant primary" ( $L_{1}$ and $C_{1}$ are in series) and "parallel resonant secondary" ( $L_{2}$ and $C_{2}$ are in parallel) as it is more suited for a voltage input excitation and voltage output rectification.

The two inductors are coupled to each other with a coupling factor $\mathrm{k}$ and the LC circuits from emitter and receiver are tuned to the same resonant frequency $f_{r}$ that can be calculated with (1) as regards to $L_{2}$. A variable source at $f_{r}$ is applied to the primary, which then resonates and creates a resonant magnetic field. When a receiver tuned to $f_{r}$ is nearby, it resonates with the emitter and power is transferred.

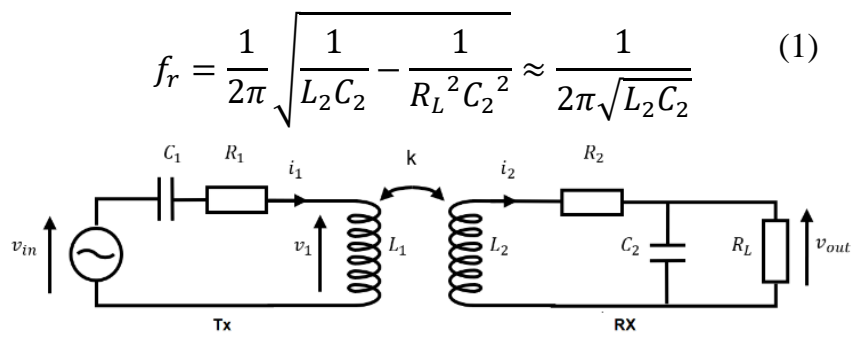

Fig. 2. Circuit model of a series-parallel resonant WPT system. $L_{i}$ and $R_{i}$, are the intrinsic inductance and resistance values of emitting and receiving coils. $C_{i}$ are the matching capacitors for resonance. $R_{L}$ is the load and $\mathrm{k}$ is the coupling coefficient between the inductors.

The Power Delivered to Load (PDL) and the Power Transfer Efficiency (PTE) are highly depending on the load value $R_{L}$, the coupling factor $\mathrm{k}$ and the quality factor of each inductor $Q_{L i}$ (2). This can be showed by the Formula (3) that allows to calculate the PTE of this system with an optimized load [9]. It shows that the PTE drops when the coupling factor k or the quality factors $Q_{L 1}$ and $Q_{L 2}$ diminishe. On the other side, if $\mathrm{k}$ decreases too much, PTE also drops down significantly because the resonant frequency changes [10]. So, these systems have a working range of $k$ where PDL and PTE stays almost stable.

If the emitting and receiving coils have the same dimensions, this range of $\mathrm{k}$ is linked to a minimum and maximum distance between receiver and emitter where power can be transferred at high efficiency. When the receiver is smaller than the emitter, depending on the difference of size, this working distance gets closer to the emitter.

$$
\begin{gathered}
Q_{L i}=\frac{2 \pi f L_{i}}{R_{i}} \\
P T E=\frac{k^{2} Q_{L_{1}} Q_{L_{2}}}{\left(1+\sqrt{1+k^{2} Q_{L_{1}} Q_{L_{2}}}\right)^{2}}
\end{gathered}
$$

In this work, we want to send power to a small moving device in a big zone that will require a big emitting inductor. Thus, the PTE will drop significantly because of the size difference between emitter and receiver. However, even if the efficiency is low, power can still be transferred. In fact, with this configuration, it is expected to get an increase in the freedom of movement of the receiver at the cost of a low efficiency. However, this type of system may be useful for applications where freedom of movement is more important than efficiency. The key question here is to get sufficient power for practical applications.

\section{EXPERIMENTAL SETUP}

\section{A. Principle of work.}

The goal of the experimental set up, shown on Fig. 3, is to power a movable device in a big area without any cable. An inductive emitting box is used to transmit power wirelessly to the volume inside the box. A 3D-MID omnidirectional receiver is able to move freely inside the box and to catch power. In order to study worst case, the power is used instantaneously without any storage element, so there is no battery to store the energy.

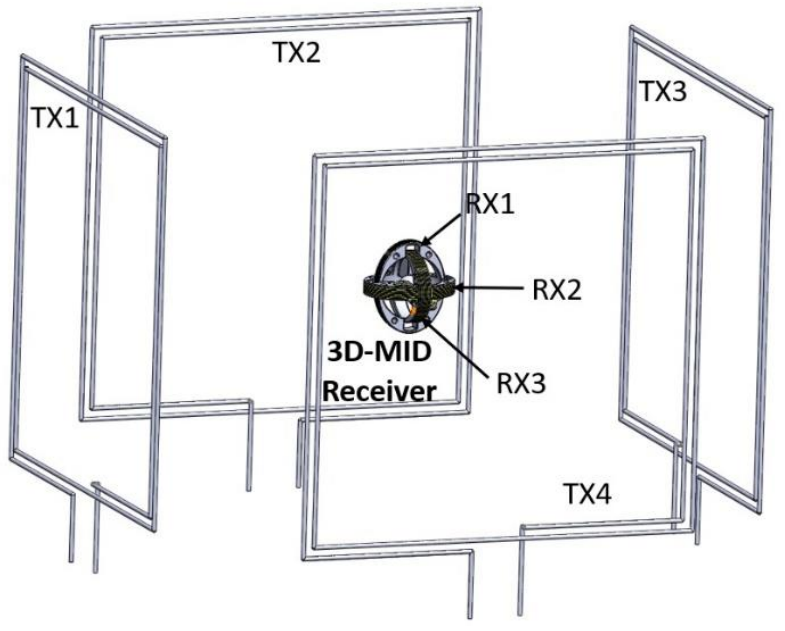

Fig. 3. Schematic diagram of an emitting box that transmit power to a 3D WPT receiver. Four coils TXi are used to transmit power from each side of the box. The receiver has 3 different inductors pointing in 3 different directions.

\section{B. Emitting box setup}

The box is made with polymer frames and panels as shown on Fig. 4. A full polymer XYZ translation stage with $\psi, \theta$ and $\varphi$ rotation is used to move the receiver in the box. No metal was used in order to reduce unwanted power loss.

The 4 emitting square inductors of $30 \mathrm{~cm}$ are glued to the vertical sides of the box. They are wired with a 2-turn copper wire that has a cross-section of $2.1 \mathrm{~mm}^{2}$. Measurements show that the inductance value $L_{1}$ and the quality factor $Q_{L 1}$ at the 
frequency of $6.78 \mathrm{MHz}$ of each emitting inductor are respectively $4.4 \mu \mathrm{H}$ and 80 .

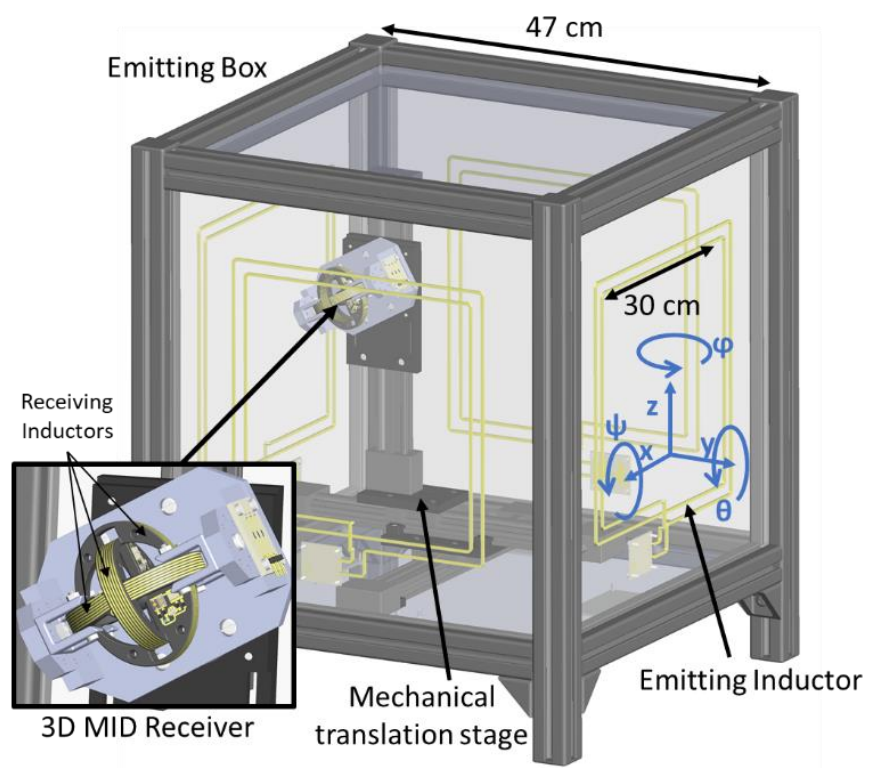

Fig. 4. Experimental emitting box with 4 emitting square inductors of $30 \mathrm{~cm}$. Inside the box, a polymer translation stage allows to move the receiver. A close view shows how the 3D-MID receiver is fixed.

Each emitting coil is in series with a high voltage trimmer capacitor $C_{1}$ to create a resonant LC circuit. (as shown on the Fig. 5). Also, they are all powered by their own high efficiency class D Zero Voltage Switching (ZVS) amplifier EPC9507 from EPC Corp. These wireless amplifiers use GaN technology in a full-bridge topology to drive the emitters LC circuit at the frequency of $6.78 \mathrm{MHz}$.
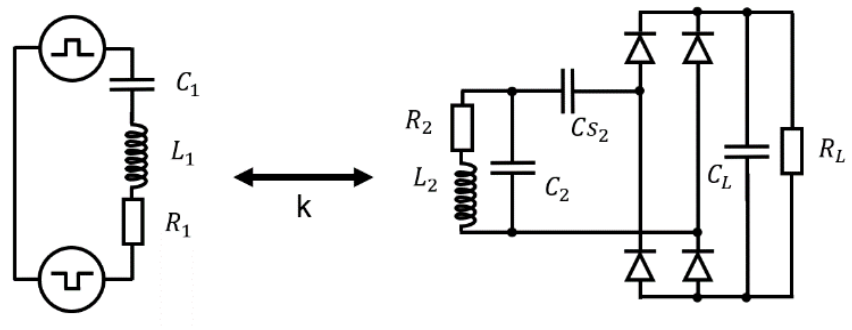

$4 \times T X$

$3 \times \mathrm{RX}$

Fig. 5. WPT circuits used to transfer power and convert it to DC. A class D amplifier powers an LC resonant circuit $L_{1}-C_{1}$. Power is then received with the $L_{2}$ inductor and $C_{2}-C s_{2}$ matching capacitors. Then voltage is rectified with 4 diodes and applied to a load $R_{L}$. In total, there are 4 emitting TX circuits and 3 receiving $\mathrm{Rx}$ circuits.

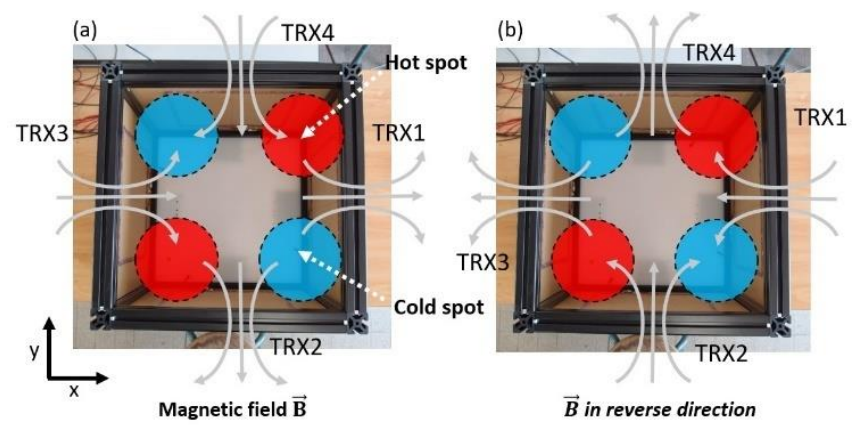

Fig. 6. (a) Directions of magnetic field during the first semi-period of sinewave excitation showing the positions of high and low energy (hot and cold spots). (b) Directions of magnetic field during the second semi-period of sinewave excitation showing that the positions of hot and cold spots remain unchanged.
The 4 emitting coils are running in phase and have a very low coupling factor $(0.0043$ for TRX1/TRX3 and TRX2/TRX4, and 0.029 for the others). Fig. 6 shows the direction of the magnetic field orientation of each emitting coil during the first and second semi-period of the sinewave excitation. With this configuration, it is expected to have 2 cold spots (opposite magnetic fields) and 2 hot spots (constructive magnetic fields) in the corners. Further study on the design of the emitting box may allow reducing this nonuniformity of the magnetic field.

\section{Design of the receiver}

The 3D-MID receiver has three $6.4 \times 5.2 \mathrm{~cm}$ elliptic inductors placed at $90^{\circ}$ from each other as shown on Fig. 7 . The inductors have 7 metallic tracks of $800 \mu \mathrm{m}$ width and $400 \mu \mathrm{m}$ spacing. Three small MID circuits are placed directly on the receiver to rectify the $\mathrm{AC}$ power from each inductor. For that purpose, a bridge of 4 Schottky diodes is used as shown on Fig. 5. A matching capacitor $\mathrm{Cs}_{2}$ is also added for matching impedance on receiving side.
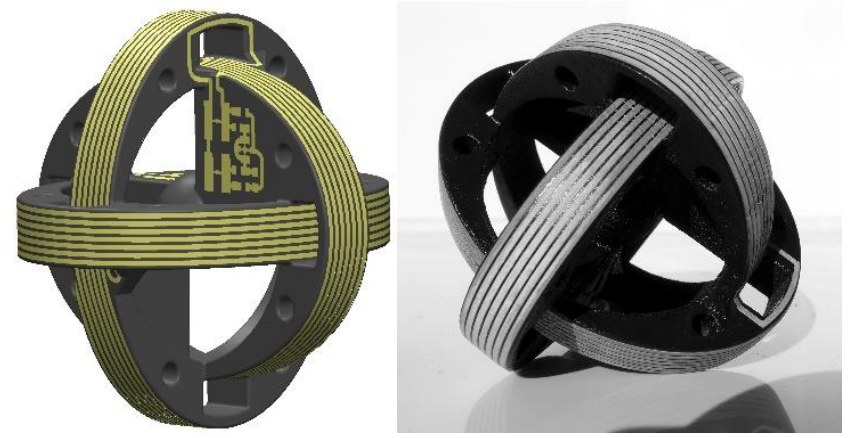

Fig. 7. 3D-MID receiver sphere with 3 inductors pointing in 3 different directions and separated by $90^{\circ}$ angle. a) CAD view of the design, b) prototype.

A previous work on the manufacturing of 3D-MID inductors for another application has showed that inductors with a quality factor higher than 100 , can be obtained with a combination of laser structuring, electroless copper deposition and electrodeposition of a copper layer of $28 \mu \mathrm{m}$ [11]. As explained previously, high quality inductors are required for inductive resonant WPT. It was estimated that a layer of copper, with a thickness between $100 \mu \mathrm{m}$ and $200 \mu \mathrm{m}$, can be sufficient to obtain a quality factor between 100 and 200 . Thus, the manufacturing process reported in [12] was applied. First the 3D-MID substrate was made by additive manufacturing with $3 \mathrm{D}$ printing laser sintering and then painted with the ProtoPaint lacquer. Then, $8 \mu \mathrm{m}$ of electroless copper was grown after laser activation with LDS-LPKF process. In the following step, the thickness of the copper was increased up to $100 \mu \mathrm{m}$ with electroplating. Lastly, an additional electroless tin plating step allowed protecting the copper tracks. The 3 receiving inductors were measured and have and inductance value $L_{2}$ of $5.7 \mu \mathrm{H}$ and a quality factor $Q_{L 2}$ of approximately 130 .

\section{MEASUREMENT RESULTS}

\section{A. Transferred power at different positions of the receiver}

Approximately 6 Watt of power was applied to each emitting coil and the receiver was moved at different positions inside the box in the following range (see Fig. 4):

- $-17.5<\mathrm{X}<+17.5 \mathrm{~cm}$ with a pitch of $2.5 \mathrm{~cm}$ 
- $\quad-17.5<\mathrm{Y}<+17.5 \mathrm{~cm}$ with a pitch of $2.5 \mathrm{~cm}$

- $\mathrm{Z}: 0,+5,+10 \mathrm{~cm}$ (for simplicity, only 3 vertical positions are considered)

The position $(X=0, Y=0, Z=0)$ is the center of the box
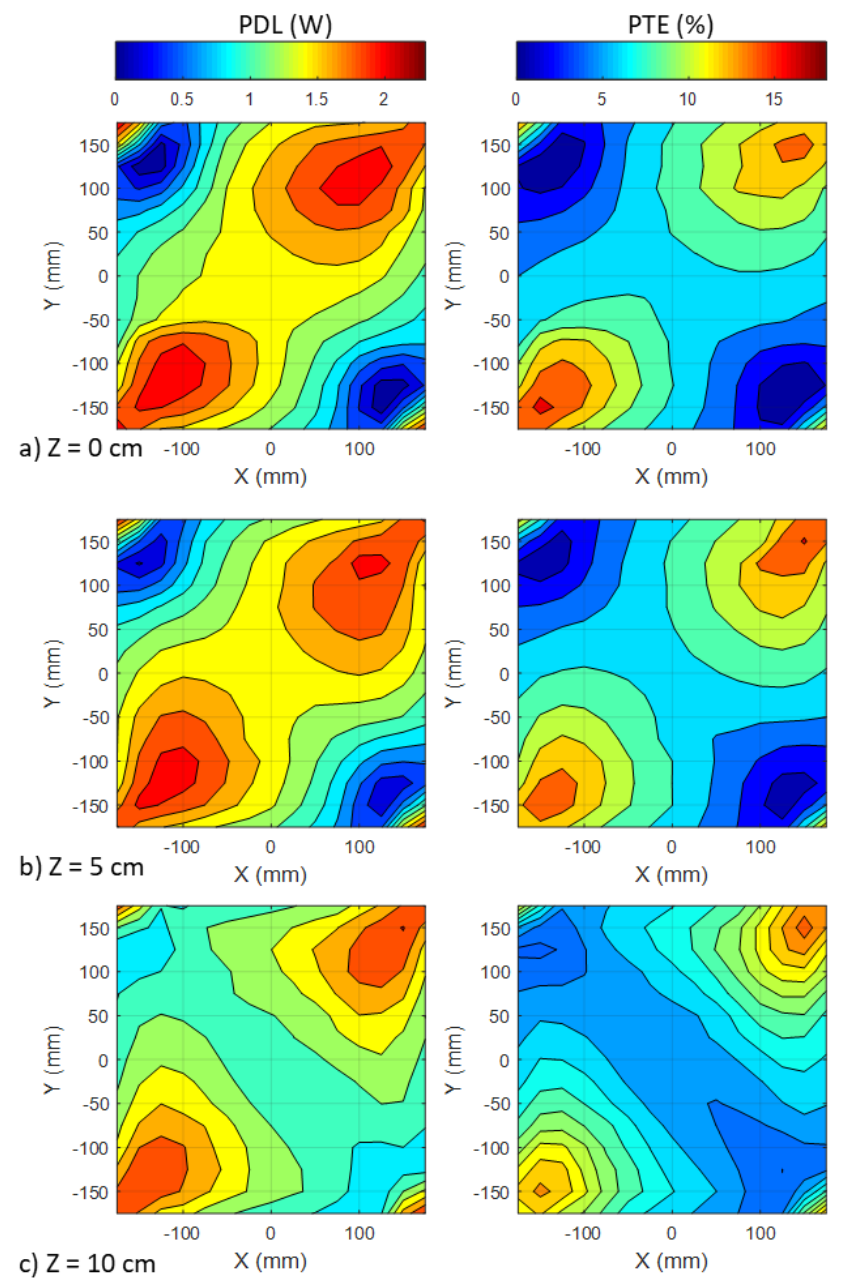

Fig. 8. PDL and PTE measured at 3 different heights a) $\mathrm{z}=0 \mathrm{~cm} \mathrm{~b}) \mathrm{z}=5 \mathrm{~cm}$ c) $\mathrm{z}=10 \mathrm{~cm}$ with the $3 \mathrm{D}-\mathrm{MID}$ receiver

The measurement results at the three $\mathrm{Z}$ levels are shown in the Fig. 8 and Table I. The measured PDL and PTE here are defined as sum of input powers from entrance of each amplifier to the sum of output powers at load after rectification. The output power was applied to a $R_{L}$ load of $68 \Omega$. As expected, the two hot spots on opposite corners $(X=12.5 ; Y=12.5)$ and $(X=-12.5 ; Y=-12.5)$, and the two cold spots on the other two opposite corners $(X=-12.5 ; Y=12.5)$ and $(X=12.5 ; Y=-12.5)$ are clearly visible in the Fig. 8 . The receiver gets a mean PDL value of $1.4 \mathrm{~W}$ with an efficiency of $7.2 \%$ on almost all positions at $\mathrm{Z}=0 \mathrm{~cm}$. On the hot spots the receiver gets up to $2.2 \mathrm{~W}$ with an efficiency of $16 \%$ and then it drops down to $0 \mathrm{~W}$ on the cold spots. As the receiver moves to higher $\mathrm{Z}$, the power drops a little bit, but it is more uniform within the area. At $\mathrm{Z}=10 \mathrm{~cm}$ the cold spots become warmer and we get $0.82 \mathrm{~W}$.

Measurement results are lower than the one obtained in our previous work in [9] where we were able to receive a mean value of $1.9 \mathrm{~W}$ power with an efficiency of $8.9 \%$ at $\mathrm{Z}=0 \mathrm{~cm}$ (with planar receiver coils made on conventional circuit boards). However, this can be explained by the fact that this $3 \mathrm{D}$ receiver was designed with only 3 coils instead of 6 coils as in [9]. Future work may allow improving this point with new geometries of 3D-MID inductances.

TABLE I. MEASURED MEAN/MAX/MIN VALUES OF OUTPUT POWER AND EFFICIENCY

\begin{tabular}{|c|c|c|c|}
\hline & Mean & Max & Min \\
\hline $\mathbf{Z}=\mathbf{0} \mathbf{~ c m}$ & $1.4 \mathrm{~W}$ at $7.9 \%$ & $2.2 \mathrm{~W}$ at $16 \%$ & $0.07 \mathrm{~W}$ at $0.28 \%$ \\
\hline $\mathbf{Z}=\mathbf{5} \mathbf{~ c m}$ & $1.4 \mathrm{~W}$ at $8.1 \%$ & $2.1 \mathrm{~W}$ at $14.5 \%$ & $0.17 \mathrm{~W}$ at $0.73 \%$ \\
\hline $\mathbf{Z}=\mathbf{1 0} \mathbf{~ c m}$ & $1.3 \mathrm{~W}$ at $7.25 \%$ & $2.0 \mathrm{~W}$ at $14.6 \%$ & $0.82 \mathrm{~W}$ at $3.7 \%$ \\
\hline
\end{tabular}

\section{B. Angular measurements}

PDL and PTE were measured at different angular $\varphi$ pitch in the central position $(X=0, Y=0, Z=0)$ and also on the cold spot and on the hot spot. Results are shown in the Fig. 9, where it can be seen, that PDL and PTE remain almost constant at any angular position. In the central position PDL and PTE have respectively a mean value of $1.44 \mathrm{~W}$ and $7.3 \%$ with a mean standard deviation of $93 \mathrm{~mW}$ and $0.0059 \%$. Our conclusion is that the power transmitted to this 3D-MID receiver is almost insensitive to angular misalignment, which a great advantage compared to receivers made by assembling conventional planar coils
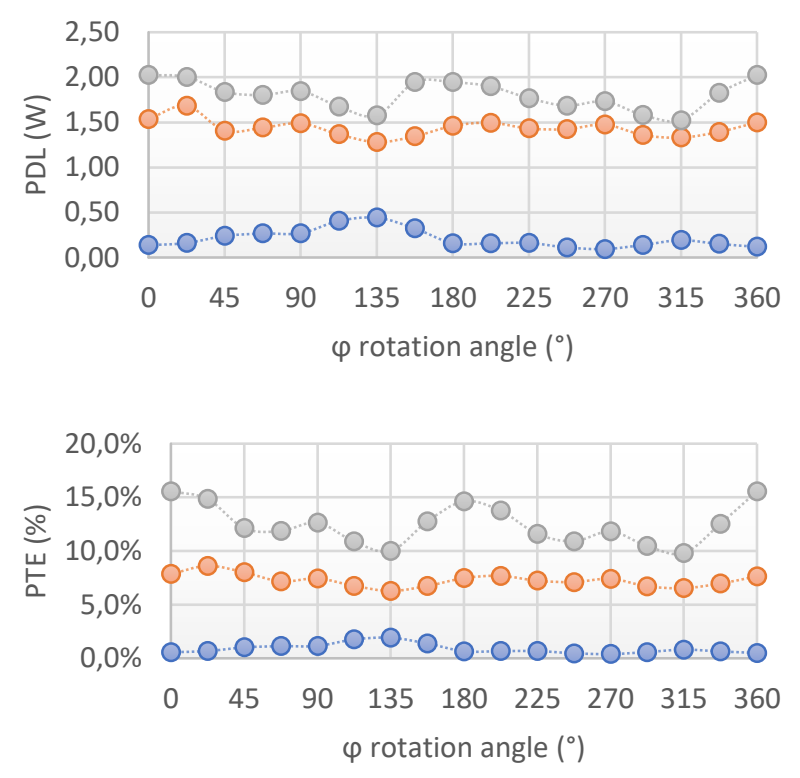

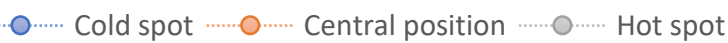

Fig. 9. Measured PDL and PTE with different pitch at $\mathrm{z}=0 \mathrm{~cm}$ and at 3 different position the central position $\left(X=Y=Z=0\right.$ and $\left.\theta=0^{\circ}\right)$, and on a cold and a hot spot, respectively $\left(X=-12.5 Y=-12.5 Z=0\right.$ and $\left.\theta=0^{\circ}\right)$ and $\left(X=12.5 Y=-12.5 Z=0\right.$ and $\left.\theta=0^{\circ}\right)$.

\section{PDL versus input power}

Fig. 10 shows the output power versus the input power with the receiver at central position in the box. The receiver gets up to $3 \mathrm{~W}$ at the cost of a lower efficiency. In fact, it is possible to get more than $3 \mathrm{~W}$ of PDL but the system faces some heating issues that need to be addressed.

\section{Possible improvements}

However, it was demonstrated experimentally that the receiver can get at least $1.4 \mathrm{~W}$ of power at almost all positions. The measured efficiency is low as expected because of the 
difference of size between the emitting coils and the receiving coils. This value is sufficient to power many devices so practical applications of this technology can be foreseen in the future.

In addition, it may be also possible to significantly increase the transmitted power by considering the improvements listed below:

- The efficiency of power will increase when the number of receivers will increase.

- The quality factor of emitting and receiving coils can be improved by increasing the thickness of copper.

- When the receiver is situated close to one side of the box, or in a cold spot, some emitting inductors can be turned off as they are not efficient. With this strategy, PTE will be highly increased at some positions.

- Cold spots and hot spots can be corrected by changing the directions of the magnetic field of each coil.

- Automatic tuning of coils can increase PDL and PTE at some positions.

- Automatic configuration of load will allow getting maximum PDL and PTE.

- Adding two more emitting inductors on the top and bottom side of the box will allow also sending more energy
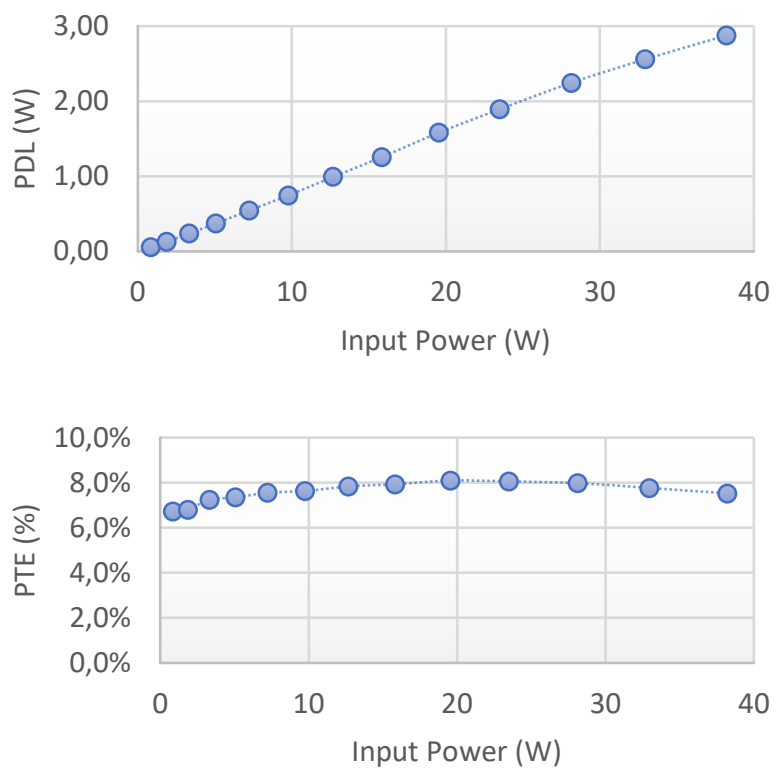

Fig. 10. Measured PDL and PTE at the central position $\left(X=Z=Y=0\right.$ and $\left.\theta=0^{\circ}\right)$ for different input power

\section{CONCLUSION}

An inductive WPT receiver has been designed and manufactured with 3D-MID coils instead of planar coils. It was shown that it can receive almost $1.4 \mathrm{~W}$ of power with an efficiency of $7.9 \%$ on most of the positions inside a half meter cubic box. This level of energy is sufficient for considering practical applications. More work is required to explore the possibilities for improving the system and some suggestions of improvements were given. We showed that the design of
$3 \mathrm{D}$ inductors can help to increase the freedom of movement of a WPT receiver and that 3D-MID technology is a key technology in manufacturing 3D WPT receivers. For wirelessly transmit information, antennas are commonly made with 3D-MID technology, so it is foreseen that 3D-MID coils may be useful in the future for wirelessly transfer energy. 3DMID inductors can be easily integrated in many electronic portable devices. They are light weighted, and they do not take too much space. This system can be seen as a preliminary work of future applications for the consumer market but it has also some direct applications in industrial automation (powering robots [12], mini robots [13][14]), medical application (body and mouse monitoring [15], implants [16], RMI [17]) and also military applications.

\section{ACKNOWLEDGMENT}

The Agence Nationale de la Recherche Technologique (ANRT) is acknowldeged for S. Kamotesov's CIFRE PhD scholarship.

\section{REFERENCES}

[1] Agbinya, Johnson I. Wireless power transfer. Vol. 45. River Publishers, 2015.

[2] Hui, S.Y., 2013. Planar wireless charging technology for portable electronic products and Qi. Proceedings of the IEEE, 101(6), pp.12901301.

[3] Ha-Van, N. and Seo, C., 2015, May. A novel cubic transmitter for multi-directional wireless power transfer. In Wireless Power Transfer Conference (WPTC), 2015 Proceedings of the IEEE (pp. 1-3). IEEE.

[4] Ng, W.M., Zhang, C., Lin, D. and Hui, S.R., 2014. Two-and threedimensional omnidirectional wireless power transfer. Proceedings of the IEEE Transactions on Power Electronics, 29(9), pp.4470-4474.

[5] Lin, D., Zhang, C. and Hui, S.R., 2017. Mathematic analysis of omnidirectional wireless power transfer-Part-II three-dimensional systems. Proceedings of the IEEE Transactions on Power Electronics, 32(1), pp.613-624.

[6] Jow, U.M., McMenamin, P., Kiani, M., Manns, J.R. and Ghovanloo, M., 2014. EnerCage: A smart experimental arena with scalable architecture for behavioral experiments. Proceedings of IEEE Transactions on Biomedical Engineering, 61(1), pp.139-148.

[7] Lee, B., Kiani, M. and Ghovanloo, M., 2015. A smart wirelessly powered homecage for long-term high-throughput behavioral experiments. Proceedings of IEEE sensors journal, 15(9), pp.49054916.

[8] S. Kamotesov, P. Lombard, V. Semet, B. Allard, M. Moguedet and M. Cabrera., 2018. Omnidirectional inductive wireless charging of a 3D receiver cube inside a box. Proceedings of the IEEE 2018 Wireless Power Transfer Conference (WPTC).

[9] Van Schuylenbergh, K. and Puers, R., 2009. Inductive powering: basic theory and application to biomedical systems. Springer Science \& Business Media.

[10] Niu, W.Q., Chu, J.X., Gu, W. and Shen, A.D., 2013. Exact analysis of frequency splitting phenomena of contactless power transfer systems. IEEE Transactions on Circuits and Systems I: Regular Papers, 60(6), pp.1670-1677.

[11] Kamotesov, S., Lombard, P., Vollaire, C., Semet, V., Cabrera, M., Dahmani, R., Veille, A. and Moguedet, M., 2016, September. Modelization and characterization of $2 \mathrm{D}$ and $3 \mathrm{D}$ mid inductors for multidirectional inductive proximity sensing. In Molded Interconnect Devices (MID), 2016 Proceefings of 12th International Congress (pp. 1-6). IEEE.

[12] O'brien, K., Scheible, G. and Gueldner, H., 2003, November. Analysis of wireless power supplies for industrial automation systems. In Industrial Electronics Society, 2003. IECON'03. Proceedings of the 29th Annual Conference of the IEEE (Vol. 1, pp. 367-372). IEEE.

[13] Karpelson, M., Waters, B.H., Goldberg, B., Mahoney, B., Ozcan, O., Baisch, A., Meyitang, P.M., Smith, J.R. and Wood, R.J., 2014, May. A wirelessly powered, biologically inspired ambulatory microrobot. In Robotics and Automation (ICRA), 2014 Proceedings of the IEEE International Conference on (pp. 2384-2391). IEEE. 
[14] Kim, D., Hwang, K., Park, J., Park, H.H. and Ahn, S., 2017. Miniaturization of Implantable Micro-Robot Propulsion Using a Wireless Power Transfer System. Micromachines, 8(9), p.269.

[15] Xu, Q., Gao, Z., Wang, H., He, J., Mao, Z.H. and Sun, M., 2013. Batteries not included: A mat-based wireless power transfer system for implantable medical devices as a moving target. Proceedings of the IEEE Microwave Magazine, 14(2), pp.63-72.
[16] A. Pacini, F. Benassi, D. Masotti and A. Canstanzo., 2018. Design of a Miniaturized Omni-Directional RF-to-dc IR-WPT. Proceedings of the IEEE 2018 Wireless Power Transfer Conference (WPTC).

[17] K. Bryon, F. Robb, S. Vasanawala, J. Pauly and G. Scott., 2018. A Wireless Power Transfer System for MRI Scanners. Proceedings of the IEEE 2018 Wireless Power Transfer Conference (WPTC). 